\title{
GCU
}

Glasgow Caledonian

University

University for the Common Good

\section{Challenges in integrating international evidence relating to stroke rehabilitation: experiences from a Cochrane systematic review}

Pollock, Alex; Campbell, Pauline; Baer, Gillian; Choo, Pei Ling; Forster, Anne; Morris, Jacqui; Pomeroy, Valerie M.; Langhorne, Peter

Published in:

International Journal of Stroke

DOI:

10.1111/ijs. 12339

Publication date:

2014

Document Version

Early version, also known as pre-print

Link to publication in ResearchOnline

Citation for published version (Harvard):

Pollock, A, Campbell, P, Baer, G, Choo, PL, Forster, A, Morris, J, Pomeroy, VM \& Langhorne, P 2014 ,

'Challenges in integrating international evidence relating to stroke rehabilitation: experiences from a Cochrane systematic review', International Journal of Stroke, vol. 9, no. 8, pp. 965-967. https://doi.org/10.1111/ijs.12339

\section{General rights}

Copyright and moral rights for the publications made accessible in the public portal are retained by the authors and/or other copyright owners and it is a condition of accessing publications that users recognise and abide by the legal requirements associated with these rights.

Take down policy

If you believe that this document breaches copyright please view our takedown policy at https://edshare.gcu.ac.uk/id/eprint/5179 for details of how to contact us. 


\section{Glasgow Caledonian University}

\section{Challenges in integrating international evidence relating to stroke rehabilitation: experiences from a Cochrane systematic review \\ Pollock, Alex; Campbell, Pauline \\ Published in: \\ International Journal of Stroke}

Publication date:

2014

Document Version

Early version, also known as pre-print

Link to publication in ResearchOnline@GCU

Citation for published version (APA):

Pollock, A., \& Campbell, P. (2014). Challenges in integrating international evidence relating to stroke rehabilitation: experiences from a Cochrane systematic review. International Journal of Stroke, 9(8), 965-7.

\section{General rights}

Copyright and moral rights for the publications made accessible in the public portal are retained by the authors and/or other copyright owners and it is a condition of accessing publications that users recognise and abide by the legal requirements associated with these rights.

- Users may download and print one copy of any publication from the public portal for the purpose of private study or research. - You may not further distribute the material or use it for any profit-making activity or commercial gain

- You may freely distribute the URL identifying the publication in the ResearchOnline@GCU portal

If you believe that this document breaches copyright please contact us at: repository@gcu.ac.uk providing details, and we will remove access to the work immediately and investigate your claim. 


\section{$\underline{\text { Title }}$}

Challenges in integrating international evidence relating to stroke rehabilitation: experiences from a Cochrane systematic review

\section{Authors}

Alex Pollock, PhD, Nursing, Midwifery and Allied Health Professions Research Unit, Glasgow Caledonian University, Glasgow, UK

Pauline Campbell, PhD, Nursing, Midwifery and Allied Health Professions Research Unit, Glasgow Caledonian University, Glasgow, UK

Gillian Baer, PhD, Department of Physiotherapy, Queen Margaret University, Edinburgh, UK

Pei Ling Choo, BSc(Hons), School of Health \& Life Sciences, Glasgow Caledonian University, Glasgow, UK

Anne Forster, PhD, Academic Unit of Elderly Care and Rehabilitation, Bradford Institute for Health Research, Bradford Teaching Hospitals NHS Foundation Trust/University of Leeds, Bradford, UK

Jacqui Morris, PhD, School of Nursing and Midwifery, University of Dundee, Dundee, UK

Valerie M Pomeroy, PhD, School of Rehabilitation Sciences, University of East Anglia, Norwich, UK

Peter Langhorne, PhD, Academic Section of Geriatric Medicine University of Glasgow, , Glasgow, UK

\section{Corresponding author details}

Alex Pollock

Nursing, Midwifery and Allied Health Professions Research Unit

Buchanan House

Cowcaddens Road

Glasgow Caledonian University

Glasgow

G4 OBA

UK

Email: alex.pollock@gcu.ac.uk

Telephone: (44)1413318100

\section{Key words}

Stroke, rehabilitation, physical therapy, systematic review, trials, Chinese trials

Conflicts of interest: none declared

Word count: 1041 


\section{Challenges in integrating international evidence relating to stroke rehabilitation: experiences from}

\section{a Cochrane systematic review}

Alex Pollock, Pauline Campbell, Gillian Baer, Pei Ling Choo, Anne Forster, Jacqui Morris, Valerie M Pomeroy, Peter Langhorne

\section{Abstract}

There are many randomised controlled trials relating to stroke being carried out in China, which are often published in Chinese language journals. A recent update to our Cochrane systematic review of physical rehabilitation after stroke included 96 trials; over half (51) were conducted in China, with 37 published in Chinese language. Analyses within this Cochrane review support the conclusion that physical rehabilitation, using a mix of components from different approaches, is effective for the recovery of function and mobility after stroke. However the inclusion of the Chinese studies had a substantial impact on the volume of evidence and, consequently, the conclusions. Within this paper we explore whether it is appropriate to draw implications for clinical practice throughout the world from evidence relating to a complex rehabilitation intervention delivered within one healthcare setting, with accompanying cultures and beliefs associated with health and disease. We explore the challenges associated with incorporating the body of evidence from China, particularly the Chinese language publications, and identify the ongoing debate about the quality of Chinese research publications. We reach the conclusion that the growing body of evidence from China clearly has important implications for future systematic reviews and evidence-based stroke care but analysis and interpretation raise challenges, and improved reporting is critical. 


\section{Challenges in integrating international evidence relating to stroke rehabilitation: experiences from}

\section{a Cochrane systematic review}

Alex Pollock, Pauline Campbell, Gillian Baer, Pei Ling Choo, Anne Forster, Jacqui Morris, Valerie M Pomeroy, Peter Langhorne

The rapidly growing number of randomised controlled trials (RCTs) published in Chinese provides a valuable resource for systematic reviews, (1) contributing potentially important evidence to inform stroke rehabilitation.(2) A recent update to our Cochrane systematic review of physical rehabilitation after stroke included 96 trials; over half (51) were conducted in China, with 37 published in Chinese language.(3) The inclusion of these international studies had a substantial impact on the volume of evidence and, consequently, the conclusions. However, it is pertinent to explore whether evidence relating to a complex rehabilitation intervention delivered within one healthcare setting, with accompanying cultures and beliefs associated with health and disease, can have implications for clinical practice in other settings throughout the world.

Our review sought to determine the relative effectiveness of different physical rehabilitation approaches aimed at improving functional independence (in activities of daily living, ADL) and motor recovery (function) after stroke.(4) The previous version of the review(4) highlighted a growing body of potentially relevant international evidence. For the current review we convened a stakeholder group of stroke survivors, carers and physiotherapists specifically to explore whether it was clinically meaningful to bring this body of international evidence together. We used nominal group techniques to reach consensus decisions(5) around the clinical relevance of synthesising international trials of different physical rehabilitation approaches within the Cochrane review. These stakeholders unanimously agreed that all international evidence relating to physical rehabilitation approaches should be integrated into the updated review. 
This decision resulted in the inclusion of 51 trials carried out in China (59 in total from Asia). Figure 1 illustrates the geographical location of the 96 included trials. Data from 27 RCTs (3423 participants) comparing physical rehabilitation to no treatment were pooled for the independence in ADL outcome and from 25 RCTs (4558 participants) relating to the motor function outcome. Almost all of this evidence came from China: 25 RCTs (3173 participants) and 23 RCTs (4308 participants) respectively. These pooled analyses demonstrated that physical rehabilitation has a significantly beneficial effect as compared to no intervention on independence in $\mathrm{ADL}$ (SMD $0.78,95 \% \mathrm{Cl}[0.58$, 0.97]) and motor function (SMD $0.81,95 \% \mathrm{Cl}[0.58,1.04])$. Analysis of available follow-up data provided some evidence that the benefits were maintained beyond the end of the intervention ( 9 studies, 540 participants, SMD $0.58,95 \% \mathrm{Cl}[0.11,1.04]$ for independence in ADL of which 7 studies, 308 participants were from China; 8 studies, 1,829 participants, SMD 1.06, 95\% Cl $[0.37,1.75]$ for motor function, of which 6 studies, 1595 participants, were from China).

Together with the results of analyses from other comparisons in this Cochrane review these data suggest that physical rehabilitation, using a mix of components from different approaches, is effective for the recovery of function and mobility after stroke.

However, many of the Chinese RCTs compared physical rehabilitation approaches with no treatment. Therefore some of the challenges to interpretation of these findings relates to whether it is appropriate to draw implications from this Chinese evidence to settings where no treatment may be considered unethical. Arguably this evidence potentially has few direct implications for settings other than those where standard care comprises no physical rehabilitation. Yet the potential value of this evidence to other international contexts may lie in the indirect implications relating to issues such as dose, content and timing of interventions. 
Incorporating the body of evidence from China, particular the Chinese language publications, provided a number of challenges. These included the resources required for translation of Chineselanguage publications and the complexity of interpreting data arising from different healthcare systems and cultures. We also experienced difficulties in searching and accessing papers published in some Chinese journals, with the British Library reporting that they were unable to locate some of the identified papers. The methods we used to assess the Chinese-language publications were arguably less robust than those we used for English-language publications, as - while all Englishlanguage publications were assessed independently by two reviewers - we relied on translations by the one member of our team who spoke Chinese. Similar limitations have also been described in a systematic review of Chinese trials of stroke rehabilitation.(2)

In addition to these practical problems associated with identifying, assessing and synthesising evidence from China, there is an ongoing debate about the quality of Chinese research publications, which is associated with reports of high levels of plagiarism and data fabrication. $(6,7)$ It has been argued that within Chinese academic institutions there is a culture of rewarding researchers according to the number of publications, whilst failing to judge publication quality.(8) Such criticisms challenge the risk of bias associated with inclusion of Chinese trials, but others argue that this problem is not limited to China. A systematic exploration of publication retractions found that more retractions, due to fraud or suspected fraud, occurred with research from the United States, Germany and Japan than China, although China was found to have the greatest number of retractions due to duplicate publication.(9)

Within our Cochrane review we conclude that our results are limited by poor reporting and substantial heterogeneity across the included trials. However if we explore in more detail our judgement of risk of bias relative to the geographical location of the trial, we do observe a difference between the 59 studies carried out in Asia and those carried out in the rest of the world (Figure 2). 
The reporting of methodological details relating to randomisation and allocation concealment was poorer in the studies from Asia; but conversely issues related to baseline differences appear better reported in these studies. From this we can only draw conclusions relating to the quality of reporting. There is clearly an urgent need for improvements in the quality of reporting of methodological details of rehabilitation trials across the whole world; but particularly in those trials from China. We therefore urge authors and journal editors to adhere to the CONSORT 2010 guidelines for the reporting of randomised controlled trials, facilitating complete and transparent reporting, and aiding their critical appraisal and interpretation.(10, 11)

In summary, our experience shows there are many RCTs relating to stroke being carried out in China, which are often published in Chinese language journals. The growing body of evidence clearly has important implications for future systematic reviews and evidence-based stroke care but analysis and interpretation raise challenges, and improved reporting is critical. 


\section{References}

1. Zhang L. A number of randomized controlled trials reported in Chinese literature are not covered in MEDLINE. . 21st Cochrane Colloquium; 19-23 September 2013; Quebec. 2013.

2. Zhang WW, Speare S, Churilov L, Thuy M, Donnan G, Bernhardt J. Stroke rehabilitation in China: a systematic review and meta-analysis. International journal of stroke : official journal of the International Stroke Society. 2014;9(4):494-502.

3. Pollock A, Baer G, Campbell P, Choo PL, Forster A, Morris J, et al. Physical rehabilitation approaches for the recovery of function and mobility following stroke. The Cochrane database of systematic reviews. 2014;4:CD001920.

4. Pollock A, Baer G, Pomeroy V, Langhorne P. Physiotherapy treatment approaches for the recovery of postural control and lower limb function following stroke. The Cochrane database of systematic reviews. 2007(1):CD001920.

5. Murphy MK, Black NA, Lamping DL, McKee CM, Sanderson CF, Askham J, et al. Consensus development methods, and their use in clinical guideline development. Health Technol Assess. 1998;2(3):i-iv, 1-88.

6. Ding Y. Chinese Academy of Sciences. In China, publish or perish is becoming the new reality. Science. 2001;291(5508):1477-9.

7. Qiu J. Publish or perish in China. Nature. 2010;463(7278):142-3.

8. Anon. Looks good on paper. A flawed system for judging research is leading to academic fraud. The Econonmist. 2013 September 28.

9. Fang FC, Steen RG, Casadevall A. Misconduct accounts for the majority of retracted scientific publications. Proceedings of the National Academy of Sciences of the United States of America.

2012;109(42):17028-33.

10. Schulz KF, Altman DG, Moher D, Consort G. [CONSORT 2010 Statement: updated guidelines for reporting parallel group randomised trials (Chinese version)]. Zhong xi yi jie he xue bao $=$ Journal of Chinese integrative medicine. 2010;8(7):604-12.

11. Schulz KF, Altman DG, Moher D, Group C. CONSORT 2010 statement: updated guidelines for reporting parallel group randomised trials. Bmj. 2010;340:c332. 